\title{
Justificativa para um novo ensino técnico
}

\author{
Justification for a new technical teaching
}

\author{
Roberto Boclin ${ }^{1}$ \\ ${ }^{1}$ Faculdade Cesgranrio | Vice-Diretoria \\ Rio de Janeiro | RJ | Brasil. Contato: roberto.boclin@gmail.com \\ https://orcid.org/0000-0002-4973-561X
}

Resumo: O artigo destaca a importância do ensino técnico e argumenta com as experiências realizadas historicamente em outros países e no Brasil. Procura dar ao Ensino Técnico autonomia e currículo próprio, independente do Ensino Médio, porém equivalente ao mesmo para fins de prosseguimento de estudos em nível superior.

Palavras-chave: Educação técnica. Politecnia. Escola do trabalho.

Abstract: The article highlights the importance of technical education and argues with the experiences historically carried out in other countries and in Brazil. It seeks to give to the Technical Teaching autonomy and own curriculum independent of the High School, but equivalent to the same for the purposes of pursuing studies at a higher level.

Key words: Technical education. Polytechnic. School of work.

DOI: http://dx.doi.org/10.1590/S1414-40772019000200004

Este é um artigo publicado em acesso aberto (Open Access) sob a licença Creative Commons Attribution Non-Commercial, que permite uso, distribuição e reprodução em qualquer meio, sem restrições desde que sem fins comerciais e que o trabalho original seja corretamente citado. https://creativecommons.org/licenses/by-nc/4.0/

Recebido em: 18 de janeiro de $2018 \quad$ Aprovado em: 23 de junho de 2019

\section{Introdução}

A Revolução Industrial na Inglaterra e a Revolução Francesa constituíram-se em movimentos que marcaram a história do Ocidente determinando profundas mudanças no processo de desenvolvimento social e histórico da nossa sociedade. Alteraram o modo de produção material e simbólico, deslocando o trabalho e o conhecimento de uma esfera a outra, ou seja, do campo para a cidade, do feudo para o burgo, do ateliê para a indústria, da igreja para o estado. 
Em relação à educação, a Revolução Francesa ao seu final, na fase Napoleônica, defendeu a universalização da escola básica a todos os servidores públicos e militares mas, instruindo-os segundo o ideal burguês de sociedade que se pretendia construir.

As ideias educacionais, a partir do final do século XVIII orientaram-se a partir de duas correntes opostas de pensamento: o positivismo representado por Augusto Comte (1908) e o materialismo histórico dialético representado por Karl Marx (2002).

Contrapondo-se ao positivismo, ao seu modelo de sociedade e ao processo de produção que se gestava sob a direção da burguesia, Karl Marx (2002) elabora o materialismo histórico dialético e, a partir da crítica à economia política e ao modelo de educação burguesa, apresenta suas ideias sobre a educação da classe trabalhadora.

Após Marx e Engels (1978) terem anunciado os princípios da educação pública socialista, estes foram desenvolvidos trinta anos depois por Vladimir Ilich Lênin (1977) e M. Pistrak (1981) no processo de implantação da teoria materialista de educação, que se apresentou com uma formulação teórico-pedagógica a qual compreende a formação integral do homem, a partir da vinculação do ensino com o trabalho produtivo.

Tal debate, inseriu-se no contexto entre a crítica à escola tradicional aristocrática, no qual a burguesia formulou as propostas de uma escola ativa e pragmática, apoiada nas teses de John Dewey (1978) e a da classe trabalhadora e seus intelectuais orgânicos, a partir das ideias de Marx e Engels (1978), que colocaram em discussão uma educação para os trabalhadores numa perspectiva politécnica.

A politecnia significa o domínio científico e técnico, ou seja, tecnológico dos processos produtivos (MACHADO, 1991).

Para o trabalhador significaria a superação da divisão do trabalho intelectual e manual e a apropriação técnica e científica dos processos de produção. A omnilateralidade proposta compreende todas as dimensões do ser humano para se alcançar o desenvolvimento integral do trabalhador.

A Escola do Trabalho, assim definida, constituiu-se, tomando o trabalho como ponto de partida para concretizar a educação politécnica. Tal experiência conta com a contribuição de vários teóricos e pedagogos socialistas e, estende-se nas décadas de 1920 e 1930 como experiência teorico-prática de educação socialista posterior à Revolução Russa de 1917.

Pistrak (1992) apresenta, a partir de sua experiência como pedagogo na Escola de Lepechinsky, ideias sobre como se constituiu a pedagogia social da escola do trabalho. A partir da ênfase nas leis gerais que regem o conhecimento do mundo natural e social, da preocupação com a realidade atual, das leis do trabalho humano, dos dados sobre a estrutura 
psicofísica dos educandos, do método dialético como uma força organizadora do mundo, este teórico sistematiza a pedagogia social da Escola do Trabalho e aponta algumas questões da prática pedagógica para a compreensão da relação entre ciência e trabalho.

A Escola do Trabalho constitui-se como a primeira experiência de Formação Integral do Trabalhador e se orienta no materialismo histórico dialético para guiar uma prática pedagógica que vise a educação do trabalhador com condições de intervir técnica e politicamente nos processos produtivos e sociais.

Nesta relação, busca-se apreender os antagonismos, as contradições postas pela sociedade capitalista no processo de construção social e histórica. O Sistema do Complexo organiza as disciplinas do ponto de vista dialético. A década de 1930 constituiu-se num período de intensa e rica discussão teórica e de enfrentamento prático das formulações propostas pela educação socialista. Nesse período foram publicados muitos livros e relatos de experiência de educação politécnica, vivenciados em várias escolas e que testemunham o interesse pela concretização das ideias propostas, porém, muitos problemas permaneciam sem solução, desafiando os pesquisadores educacionais.

Por outros caminhos semelhantes quem pretender pesquisar as origens da educação profissional certamente irá encontrá-las na Reformpädagogik da virada do século nos estudos de Georg Kerschensteiner (1899) e sua "Arbeitschule", nas controvérsias com educadores e filósofos, todos envolvidos com as questões da "Escola Nova" onde merecem especiais citações Pestalozzi (1946) e Dewey (1978).

As próprias origens metodológicas da formação profissional no Brasil, foram muito influenciadas pelas ideias "revolucionárias" dos pesquisadores citados e, muito especialmente, pela Escola do Trabalho de Kerschensteiner (1912), na Baviera, polo pedagógico da formação profissional na Alemanha, na Áustria e na Suíça. A Escola do Trabalho alemã fundamentava seus princípios no pressuposto de que o desenvolvimento das habilidades manipulativas exercia papel estratégico na formação do cidadão. Prevalecia a convicção de que a formação profissional tinha como objetivo a preparação de um cidadão apto a desempenhar o seu papel na sociedade, seja pela sua promoção social como pela sua valorização profissional. Os resultados colhidos confirmaram as expectativas mais otimistas (KERSCHENSTEINER, 1928).

O conceito reformista de Educação e Trabalho, de Kerschensteiner (1912), buscava uma relação melhor entre o social da educação e o econômico do trabalho, sendo a escola a passarela pedagógica entre os dois entes de mesma grandeza. Alguns menos atentos ao pensamento reformista enveredaram por caminhos mais pragmáticos e menos conceituais 
como o da educação para o trabalho que parecia se influenciar mais pelo ambiente empresarial do que pelos aspectos pedagógicos. Logo ficou claro, quando a noção de trabalho no processo educacional e no discurso pedagógico foi adquirindo uma compreensão mais substancial, que a escola para o trabalho não era uma consequência da pedagogia reformista.

A concentração nas necessidades empresariais conduziu inevitavelmente à marginalização da escola e dos domínios da pedagogia, na organização de uma formação funcional em prazos curtos e de resultados imediatos para os alunos e empregadores. Ainda assim nunca foi possível estabelecer os perfis de Qualificação, que fossem confiáveis e incontestáveis, ou mesmo, prognósticos garantidos de que poderiam ser convertidos em adequados programas de formação. Recentemente, nos últimos anos, a questão se agravou em decorrência das velocidades do progresso da ciência e da tecnologia, que alterando substancialmente as exigências das empresas tornou impraticável a atualização dos programas de Qualificação, formulados como uma perspectiva de ajuste fiel entre as demandas e as ofertas de conhecimento. São compreensíveis as influências do progresso econômico na formulação de projetos de formação da "força de trabalho", como a pedagogia das profissões comprometida com os conceitos de Qualificação, identificados com as necessidades das empresas na visão imediatista e indeterminada de uma perspectiva de exigências, limitando a questão às relações de trabalho nas empresas.

Do ponto de vista um tanto pragmático o que de fato ocorreu, nos últimos sessenta anos, foi o processo de levar-se a Escola para o Trabalho restringindo-se a sua função formadora aos aspectos circunstanciais do negócio, das habilidades, conhecimentos e capacidades de uso imediato e direto.

Ao contrário, nos pedagogos reformistas clássicos, como Maria Montessori, a formulação é inversa, ou seja, trazer o Trabalho para a Escola, segundo o princípio de que o homem forma-se mais precisamente por meio do trabalho, cujo significado educativo permite a sua transposição para o ambiente da escola.

A discussão passa então para o contexto pedagógico do Trabalho e seu papel educacional na formação profissional, na tentativa conciliadora de uma associação de atributos sociais e econômicos.

A necessidade de se criar uma cultura própria dos trabalhadores, por outro lado, relaciona-se com o apelo de Antonio Gramsci (1999), italiano da Sardenha, por um tipo de educação que permite o surgimento de intelectuais que partilhem das paixões das massas de trabalhadores. Neste aspecto, identifica-se com os princípios dos que consideram Gramsci 
(1999) como uma referência, para a formação profissional. Seu sistema educacional pode ser considerado como popular e foi de algum modo absorvido pelo brasileiro Paulo Freire.

$\mathrm{Na}$ França e na União Européia, nos dias atuais, o modelo adotado identifica-se com os princípios do nosso pensamento: O Conselho Europeu de Lisboa, em Março de 2000, afirmou que a Europa deve dotar-se com a "economia do conhecimento mais concorrencial e mais dinâmica do mundo". A França fez evoluir o respectivo sistema de formação e certificação profissionais nessa perspectiva européia.

Os diplomas profissionais da educação nacional francesa, classificados em cinco níveis, validam competências e conhecimentos. À formação profissional inicial segue-se à formação geral, equivalente ao nosso atual fundamental e prepara os jovens para se inserirem num emprego qualificado, de operário a engenheiro.

O sistema de educação francês divide-se em três etapas: Escola Primária, Ensino Secundário e Ensino Superior. Dos 6 aos 16 anos de idade a educação é obrigatória, gratuita e laica. Esta etapa inclui o Ensino Fundamental e parte do Ensino Médio.

As crianças começam a educação pré-escolar entre os dois ou três anos de idade. Durante esta etapa, desenvolvem e aperfeiçoam o idioma e começam a aprender as noções básicas de Matemática, leitura e escrita. A socialização é um aspecto fundamental neste nível.

A Escola Primária recebe as crianças entre 6 e 11 anos de idade e oferece uma educação mista. As crianças continuam desenvolvendo suas habilidades na educação formal um pouco mais estruturada, com cursos muito variados e didáticos.

O Ensino Secundário recebe os alunos da Escola Primária sem necessidade de realizar nenhuma prova de admissão. Os primeiros quatro anos são cursados no collège e são obrigatórios. Os três anos seguintes são cursados no lycée e neste nível os alunos podem escolher entre três itinerários: Geral (para ir à universidade), Tecnológico (para estudos técnicos superiores) ou Profissional (para ingressar no mercado profissional).

Ao finalizar esta etapa, é realizado um exame chamado Baccalauréat, que serve também como exame de ingresso na universidade.

O Ensino Superior é ministrado principalmente nas universidades e divide-se em Graduação (3-4 anos), Mestrado (1-2 anos) e Doutorado (4 anos).

A formação profissional contínua dirige-se a todas as categorias de adultos ativos, empregados, à procura de emprego, funcionários, trabalhadores independentes e chefes de empresa. Permite-lhes reforçar ou adquirir um nível de qualificação reconhecido. A validação das aquisições da experiência permite obter uma certificação profissional através do reconhecimento das competências e dos conhecimentos adquiridos durante o exercício de uma 
atividade, remunerada ou não. Estas diferentes vias permitem responder às necessidades dos diferentes públicos à procura de qualificação, independente da sua idade, nível escolar ou experiência. Tornam possível uma verdadeira formação durante toda a vida. São as vias de formação depois do colégio. Na França, dos seis aos onze anos de idade, os jovens frequentam a escola elementar. Em seguida, entram no colégio para quatro anos de ensino e até os dezesseis anos de idade. No colégio, podem orientar-se para duas vias:

a) a via geral e tecnológica: os alunos preparam, no liceu, o exame do diploma de ensino secundário geral ou tecnológico. Esta via visa o prosseguimento de estudos no ensino superior;

b) a via profissional: os alunos preparam, em dois anos, um certificado de aptidão profissional que permite entrar no mundo do trabalho ou prosseguir estudos tendo em vista um diploma de ensino secundário profissional, ou o mesmo diploma em três anos que permite, também, entrar no mundo do trabalho e prosseguir estudos.

Os jovens podem obter esses diplomas quer no Liceu Profissional, quer no âmbito de um contrato de aprendizagem. No liceu profissional, a preparação dos diplomas compreende ensinos gerais, ensinos profissionais teóricos e práticos, atividades de projeto e períodos de formação em ambiente profissional:

a) os ensinos gerais agrupam as letras, a história-geografia, as matemáticas, as ciências físicas, uma (ou duas) língua(s) viva(s), as artes aplicadas, a educação física e desportiva e um ensino de "prevenção, saúde, ambiente";

b) os ensinos profissionais teóricos e práticos permitem adquirir as competências e os conhecimentos específicos a cada certificado de aptidão profissional ou diploma do ensino secundário profissional;

c) as atividades de projeto visam, através de uma realização concreta em ligação com os ensinos gerais ou profissionais, o desenvolvimento de capacidades relativas à tomada de responsabilidade dentro de uma equipe, à organização e à gestão do tempo e à criatividade;

d) os períodos de formação em meio profissional são obrigatórios e são tidos em conta para a passagem do diploma. A duração varia consoante a finalidade do diploma e a especialidade (de 12 a 22 semanas);

e) relativamente ao certificado de aptidão profissional, a formação compreende 300 horas, ao longo de dois anos, 420 a 560 horas das quais são dedicadas ao período de formação em meio profissional (12 a 16 semanas);

f) relativamente ao diploma do ensino secundário profissional, a formação compreende 3 400 a 3500 horas, ao longo de três anos, 770 horas das quais são dedicadas ao período de formação em meio profissional (22 semanas). 
A Formação Profissional não seria mais exclusiva das necessidades das empresas, já que essas variarão muito aceleradamente e, ao mesmo tempo, conhecimentos relacionados com o desempenho estarão mais bem situados no ambiente e na abstração das escolas que são os locais mais adequados para essas finalidades, em oposição à empresa. A educação continuada será estratégia da escola e da empresa na desejável conciliação.

Quem pesquisar a educação brasileira nos tempos recentes deverá, inevitavelmente, concluir que a sua evolução não acompanhou o processo de desenvolvimento econômico do País e, ao contrário, andou sempre na direção oposta, sendo seguramente responsável por parcela ponderável dos fracassos das políticas sociais empreendidas que, afinal, conduziram ao quadro lamentável de pobreza, miséria, alienação e exclusão de representativo segmento da nossa população.

Se de um lado verificou-se uma acelerada expansão do sistema educacional pressionado pela demanda social de educação, de outro é insofismável admitir que qualitativamente, por deficiências estruturais, políticas elitistas, péssimo rendimento do sistema escolar e outras mazelas o processo caminhou em oposição às demandas decorrentes do desenvolvimento. Para uma compreensão melhor da evolução da educação brasileira o ponto de partida é a criação, em 1924, da ASSOCIAÇÃO BRASILEIRA DE EDUCAÇÃO $\mathrm{ABE}$, reunindo educadores de ideias renovadoras influenciadas por um movimento reformista, no início do século, na Europa e nos Estados Unidos, denominado de Escola Nova. Heitor Lira, Carneiro Leão, Edgard Sussekind de Mendonça, Lourenço Filho, Sampaio Dória, Fernando Azevedo, Anísio Teixeira e outros criaram a ABE (1924) com o objetivo de reivindicar medidas consideradas inadiáveis tais como a laicidade da educação, a gratuidade do ensino e sua obrigatoriedade e a coeducação.

Foi um período polêmico, principalmente pela reação dos educadores religiosos que monopolizavam a educação das elites e sentiam-se ameaçados pelas ideias renovadoras.

A partir de 1922 começaram a surgir as Reformas em vários Estados: em Pernambuco, no Ceará, em São Paulo, no Distrito Federal, em Minas Gerais e na Bahia, que constituíam o prenúncio de uma grande reforma de caráter nacional.

O movimento reformista iria culminar com o Manifesto dos Pioneiros da Educação Nacional ou da Escola Nova como foi denominado, em 1932, apresentando as propostas que desde 1924 eram debatidas e que tinham o comando de Fernando Azevedo e o apoio de 26 notáveis educadores. Sob a égide do Governo Provisório, em 1930, era constituído o Ministério da Educação e da Saúde Pública tendo Francisco Campos como Ministro e muitas esperanças de mudanças. 
De fato, em abril de 1931, um conjunto de Decretos que passou a chamar-se de Reforma Francisco Campos, promove a primeira intervenção legal de âmbito nacional na educação brasileira.

Ainda que de uma certa forma restrita na sua intervenção a Reforma abrangeu:

- $\quad$ A criação do Conselho Nacional de Educação

- $\quad$ A organização do ensino superior e o regime universitário

- $\quad$ A organização da Universidade do Rio de Janeiro

- $\quad$ A organização do ensino secundário

- $\quad$ A organização do ensino comercial e a criação da profissão de Contador

- Consolidação da organização do ensino secundário.

Embora com méritos inegáveis a reforma não abrangeu o ensino primário nem a formação profissional e o ensino técnico e também não cogitou do ensino normal, sendo seletiva, elitista e aristocrática. No que diz respeito ao ensino superior embora existente desde os idos de 1908 e com a criação da Universidade do Paraná em 1912, a do Rio de Janeiro, em 1920 e a de Minas Geris em 1927, o fato é que todas resultavam da agregação simples de Faculdades de Direito, Medicina e Engenharia, sem a concepção universitária.

Com a aprovação do novo Estatuto das Universidades Brasileiras e apesar da reorganização da Universidade do Rio de Janeiro, somente em 1934 foi criada a primeira Universidade no conceito da reforma, qual seja a Universidade de São Paulo. Em 1935 Anísio Teixeira cria a Universidade da Bahia e no mesmo ano surge a de Porto Alegre; a primeira com uma Faculdade de Educação e a segunda com uma de Economia, além do Direito, da Medicina e da Engenharia.

Do ponto de vista regimental a reforma do ensino superior contemplava a figura do Reitor, do Conselho Universitário, da Assembleia Universitária e da Direção das Escolas. Criou a carreira de Catedrático, de Auxiliar de Ensino e de Livre Docente. Organizou os currículos em três fases: o normal, os equiparados e os de aperfeiçoamento e especialização.

No entanto, manteve a falta de diversificação do ensino superior ao exigir a presença dos cursos de Direito, Medicina, Engenharia e Educação e Letras reforçando a aristocracia do ensino e não levando em conta as novas demandas de natureza econômica, próprias do desenvolvimento.

Quanto ao ensino secundário, a reforma extinguiu os preparatórios e promoveu profundas mudanças na organização do ensino que passou a ter: 
a) o ciclo fundamental com 5 anos;

b) os ciclos complementares de 2 anos com direcionamentos curriculares específicos para o Direito, a Medicina, Odontologia e Farmácia e para a Engenharia e Arquitetura.

Tratou de oferecer uma formação básica no fundamental, sendo propedêutico no complementar.

Foi implantado um sistema de avaliação rigoroso, com arguições mensais, provas bimestrais e exames finais.

Criou-se o cargo de Inspetor de ensino com atribuições e normas centrais e um rígido sistema de inspeção escolar. Embora tenha sido uma Reforma no sentido abrangente não se livrou da excessiva centralização e dependência ao poder central.

No âmbito do ensino comercial foram organizados os cursos médios e os superiores. Os primeiros em dois ciclos, o $1^{\circ}$, propedêutico em 3 anos e o segundo, técnico variando entre 1 e 3 anos, formando secretários, guarda-livros e peritos-contadores e o Curso Superior, em 3 anos, voltado para Finanças.

Se a Reforma Francisco Campos não foi completa, ainda muito influenciada pela conjuntura política dominante, inegavelmente foi o primeiro passo para as mudanças que se sucederiam nos anos seguintes com as Constituições de 1934 e 1937.

A Constituição de 1934 recebeu vantajosas influências dos Renovadores vindo a ser considerada uma vitória dos integrantes do Manifesto de 1932. Incorporou a fixação de um Plano Nacional de Educação onde estavam presentes a descentralização do ensino pelos Estados, a gratuidade do ensino e o ensino primário integral, cabendo à União a fixação das diretrizes gerais. Ainda sob o domínio de pensamentos conservadores destinou o ensino profissional às classes menos favorecidas, mantendo princípios socialmente discriminadores.

Durou pouco a conquista dos reformadores já que, em 1937, a Carta Magna do Estado Novo viria a moderar substancialmente as ênfases, procurando conter a expansão do ensino, permitindo o ensino religioso como matéria do currículo ordinário das escolas e suavizando outras conquistas anteriores. O ensino gratuito, por exemplo, foi admitido para os que comprovassem carência de recursos.

Viveu-se um período de estagnação até 1942, quando o então Ministro da Educação do Governo Vargas, Gustavo Capanema, inicia uma nova Reforma intitulada de Leis Orgânicas do Ensino, constituída de quatro Decretos que são seguidos, no Governo José Linhares, após a queda de Vargas, por outros três pelo Ministro Raul Leitão da Cunha, implantados entre 1942 e 1946 e que verdadeiramente promoveram profundas mudanças na educação brasileira. 
Os quatro primeiros instituíram o Ensino Industrial, a implantação de Escolas Técnicas Federais em todo o País, o Ensino Comercial, o Ensino Secundário e a criação do SENAI e outros três, o Ensino Primário, o Ensino Normal e o Ensino Agrícola.

Percebe-se no exame dos documentos legais as propostas da Escola do Trabalho citada anteriormente e a influência marcante do pensamento dos integrantes do Manifesto de 32, enquanto a educação nacional engaja-se no Ensino Médio e Profissional como prioridades de governo. Logo a seguir era criado o SENAC, em 1946, compondo o quadro de uma filosofia humanista tecnicista moderna que prevaleceria por muitos anos. Do ponto de vista curricular e resumidamente, o Ensino Secundário passou a ser composto de dois ciclos; o primeiro, Ginasial com quatro anos e o segundo, com três anos, dividido entre Clássico e Científico.

É óbvio considerar o caráter de cultura geral e humanística da proposta que claramente destina a formação secundária ao ingresso nos cursos superiores deixando para o ensino industrial a função preconceituosa de terminalidade profissional a nível médio, sem a necessária autonomia curricular e de prosseguimento de estudos.

Os ensinos, industrial, comercial e agrícola por sua vez foram organizados com quatro anos de fundamental e três ou quatro de técnico com estrutura curricular própria independente e um ano de formação pedagógica para a preparação de professores, neste caso em caráter opcional e de notável percepção de formação docente de natureza técnica. Ao SENAI e ao SENAC coube o papel de treinamento e formação profissional, como obrigação dos empregadores e preferencialmente para os jovens concluintes do ensino primário e aos trabalhadores empregados.

O ensino primário pioneiro em suas diretrizes nacionais foi organizado em Fundamental, com quatro anos e Complementar com um ano destinado a crianças entre 7 e 12 anos e o Supletivo de dois anos para adolescentes e adultos que não receberam esse nível nas idades oportunas. Exerceu importante papel no combate ao analfabetismo.

$\mathrm{O}$ ensino normal teve centralizadas as suas diretrizes destinadas à formação de professores para o ensino primário e foi dividido em dois ciclos; o primeiro com a duração de quatro anos visando a formação de Regentes de ensino primário e o segundo, com duração de três anos visando à formação de professores próprios das Escolas Normais e dos Institutos de Educação.

A Constituição de 1946, com o retorno a realidade democrática eminentemente liberal, consagrou a necessidade de uma nova Lei de Diretrizes e Bases da Educação, enquanto fortalecia os princípios de obrigatoriedade do ensino, gratuidade do ensino primário e obrigações explícitas aos empresários quanto ao ensino e ao treinamento de seus empregados. 
A educação brasileira passou a ser objeto da preocupação dos políticos e governantes no período entre 1948 e 1961 quando se discutiu no Congresso o projeto de lei do Professor Lourenço Filho, a pedido do então Ministro Clemente Mariani.

Em 20 de dezembro de 1961 é aprovada a Lei 4024, de Diretrizes e Bases da Educação Nacional, consagrando a estrutura anterior com pequenas alterações como a criação do ensino pré-primário com maternais e jardins de infância e o ensino médio subdividido em ginasial de 4 anos e colegial com 3 anos. De fato nada mudou.

Com o período ditatorial instalado a partir de 1964 e as crises estudantis frequentes decorrentes da contestação ideológica e da defasagem entre a demanda por cursos superiores e a oferta de um sistema universitário envelhecido gerando a figura dos excedentes, concluintes do ensino médio sem perspectivas de qualificação profissional e um ensino profissional sem prestígio junto à população e à classe empresarial, o governo adotou medidas julgadas corretoras, mas que de fato resultaram em grande fracasso educacional. A expansão do ensino superior privado foi estimulada fortemente, com expressivo crescimento quantitativo de cursos e vagas porém com qualidade quase sempre insatisfatória, resultando na formação de quadros profissionais de nível superior sem qualificação e emprego.

$\mathrm{Na}$ mesma vertente e sob o impacto das ideias tecnicistas é aprovada a Lei 5692 de 1971, de Diretrizes e Bases do Ensino de $1^{\circ}$ e $2^{\circ}$ Graus, com obrigatoriedade de iniciação ao trabalho no $1^{\circ}$ Grau e profissionalização no $2^{\circ}$. Um outro fracasso uma vez que nem o sistema de ensino público e nem o privado tinham recursos e infraestrutura compatíveis com a proposta e muito menos professores preparados, além de uma centralização metodológica impraticável.

A Lei 5692 arrastou-se por 25 anos, com consequências perversas para a formação da nossa juventude, prejudicada e iludida, por um sistema absolutamente teórico, cujo benefício residual foi o de valorizar a educação profissional, ainda que a submetendo a um rígido sistema, incompatível com o progresso da ciência e da tecnologia.

Finalmente chegamos ao ano de 1996 com a nova LDB - Lei 9394/96, que depois de mais de dez anos de discussões, alterações e emendas tornou-se fruto de uma proposta substitutiva do Senador Darcy Ribeiro, alterada em alguns dos seus artigos, mas imaculada no seu propósito principal e que introduz profunda revisão conceitual da educação brasileira.

A autonomia das escolas é estimulada com liberdade na elaboração da proposta pedagógica, na elaboração dos seus regimentos e na reclassificação de seus alunos, independentemente de escolarização anterior. O período letivo passa a ter 800 horas e 200 
dias úteis na educação básica e um mínimo de 200 dias letivos no ensino superior. A frequência escolar é de $75 \%$ do total de horas letivas com o controle pela escola.

Aproveitamento de experiências extra-escolares, tanto na educação básica, como na educação profissional e o notório saber no ensino superior.

Valoriza a educação profissional e estabelece currículos diferenciados para o ensino médio e os cursos técnicos e, de outro lado, já na sua regulamentação, propõe nova organização em caráter modular para os mesmos. Reestrutura a educação superior e estabelece classificação inovadora para as instituições - Universidades, Centros Universitários, Faculdades Integradas, Faculdades, Institutos Superiores e Escolas Superiores. O Ensino a Distância merece tratamento e importância especial.

Outras muitas inovações foram contempladas na nova LDB, mas somente o tempo poderá aferir a sua propriedade e os seus resultados.

De tudo o que foi dito constata-se que a Educação Técnica e o Ensino Profissional são ainda pouco importantes para os congressistas e mesmo para a população que afinal sonha com um filho "doutor" seja no que for, mesmo desempregado.

As realizações internacionais de sucesso da formação técnica não tem atraído os legisladores a enfrentar com determinação as mudanças estratégicas que, à semelhança do modelo Capanema de 1940, são necessárias para dar autonomia didática aos cursos técnicos, com a equivalência curricular ao ensino médio e abrindo as portas para uma formação técnica construtora de uma classe social e econômica fundamental para o progresso do País.

Quem pesquisar a educação brasileira nos tempos recentes deverá, inevitavelmente, concluir que a sua evolução não acompanhou o processo de desenvolvimento econômico do País e, ao contrário, andou sempre na direção oposta, sendo seguramente responsável por parcela ponderável dos fracassos das políticas sociais empreendidas que, afinal, conduziram ao quadro lamentável de pobreza, miséria, alienação e exclusão de representativo segmento da nossa população.

Se de um lado verificou-se uma acelerada expansão do sistema educacional pressionado pela demanda social de educação, de outro é insofismável admitir que qualitativamente, por deficiências estruturais, políticas elitistas, péssimo rendimento do sistema escolar e outras mazelas, o processo caminhou em oposição às demandas decorrentes do desenvolvimento. 


\section{Referências}

ABE. ASSOCIAÇÃO BRASILEIRA DE EDUCAÇÃO. Ata da $\mathbf{1}^{\mathbf{a}}$ Sessão. Rio de Janeiro, 22 de outubro de 1924.

COMTE, Auguste. Cours de Philosophie Positive. Dublin: Schleicher Freres, 1908.

DEWEY, J. Democracia e Educação. São Paulo: Editora Nacional, 1978.

GRAMSCI, Antonio. Cadernos do Cárcere. Editora Civilização Brasileira, 1999.

KERSCHENSTEINER, Georg. Betrachtunger zur Theorie dês Lehrplans. Munich: C. Gerber, 1899.

KERSCHENSTEINER, Georg. Die schule der zukunft eine arbeitsshule. Berlin: Leipzig, 1912.

KERSCHENSTEINER, Georg. Essência e valor do Ensino Científico - Natural. Rio de Janeiro: Athena, 1928.

LÊNIN, V. I. Sobre educação. Lisboa: Seara Nova, 1977.

MACHADO, Lucília Regina de Souza. A politecnia nos debates pedagógicos soviéticos das décadas de 20 e 30. Teoria e Educação, Porto Alegre, n. 3, p. 151-174, 1991.

MARX, Karl; ENGELS, Friedrich. Crítica da educação e do ensino. Lisboa: Editora Moraes, 1978.

MARX, Karl. O Capital: crítica da economia política. 19. ed. Rio de Janeiro: Civilização Brasileira, 2002. Livro I, v. 1.

PESTALOZZI, J. H. Antologia de Pestalozzi. Buenos Aires: Losada S. A., 1946.

PISTRAK, E. Fundamentos da Escola do Trabalho. São Paulo: Brasiliense, 1981.

PISTRAK, E. Textos sobre educação e ensino. São Paulo: Moraes, 1992. 